\section{Training in urology}

SIR,-The letter from the president of the Association of Surgeons in Training (12 May, $p$ 1281) raises a number of important issues. There is no doubt that there is at present a serious imbalance between the number of senior registrars in training in urology and expected consultant vacancies. This discrepancy is fully appreciated by both the senior registrars and the Committee for the Development of Urological Services of the British Association of Urological Surgeons. However, we cannot agree with the solutions which Mr Logie puts forward.

The president and council of BAUS are committed to encouraging an increase in the number of "pure" urological consultant appointments. The senior registrars are in full agreement with this, and a recent poll has shown that $95 \%$ of those in training at present are prepared only to apply for "pure" urological appointments and not for posts offering a mixture of general surgery and urology. We recognise that only by increasing the number of urologists in England and Wales to provide at least the same ratio of urologist, per head of population as already exists in Scotland can our patients be offered the best standard of treatment available. If the decision is taken to continue to advertise mixed appointments and if attempts are made to train surgeons for such posts the penalty would be increased mortality and morbidity. Those who advocate such a course must be honest enough to recognise this fact and to make sure that it is understood by both patients and medical politicians.

In the interest of patients there can be only one solution ald that is the continued increase in the number of consultant urologists. All urology should be performed by properly trained urological surgeons. Only in this way will the lot of those with urological disease improve. The cost effectiveness of urological units is well established.

Urological senior registrars will not willingly tolerate any chang : that will prevent the fulfilment of the ir proved standard of care which could be made available by an expansion in "pure" urology.

\section{Hugh Whitfield}

D L P REES

David TOLLEY

ROBERT BLACKLOCK Committee of Senior Registrars in Training in Urology

Department of Urology,

St Bartholomew's Hospital London EC1A 7BE

SIR,-My $B M F$ arrived today and I noted Minerva's remarks (12 May, p 1290) about quality of care in the NHS and also the letter from Mr J R C Logie (p 1281) on "Training in urology." It occurred to me that Britons have become accustomed to adversity to the extent they have become r,roud of it and even defend the NHS quite blindly. Before leaving Ontario, where I practised urology for 23 years, I was a member of the Province of Ontario urology manpower committee. There seems to be a comfortable but not overadequate number of urologists practising there for a population of 13 million. This number has stayed static more or less at about 153 . It seems incredible to me that a country with the population of England and Wales should have only 127 consultants and 31 senior registrars. One could therefore argue that there are grossly insufficient numbers of full-time urologists to provide the "best" care for all without the necessity for private care. This is not to deprecate the standard of care given by general-surgeon urologists, but surely they may be in the same position of trying to provide more good care than their numbers allow.

One sometimes gets the impression that some British doctors are becoming like gambling men-"We always lose but it's the finest sport in the world."

If a quarter to a third of urological work is done by general surgeons, where is the justification for not making more urology consultant posts even at the expense (regrettably) of general surgical posts? From this distance it would seem that there exists some form of insanity prevalent among British "planners" and "administrators." Could that dread disease be socialism, which they are trying so hard to export to this continent?

We do have our problems here, too: it sometimes rains in South Carolina.

Donald Paine

Hartsville, South Carolina 29550

\section{Dehydration and thromboembolism}

SIR,-We were interested to read Minerva's comments on dehydration and pulmonary emboli (28 April, p 1153). Recently a fit, slim, active 29-year-old airline pilot who regularly plays squash at county level and who never flies for more than three hours at a time was admitted to hospital with pleuritic pain and haemoptyses. The chest radiograph showed a wedge-shaped opacity at the right base, lung scans showed both absent ventilation and perfusion in this area, and a venogram showed a thrombus in the right popliteal vein, although clinically there were no local signs. Full haematological studies have shown no blood abnormality.

Perhaps the combination of repeated muscular trauma and the dehydration associated with strenuous physical exercise may have been important factors in this case.

DAPHNE LINE Nicola WhitakeR

\section{Wexham Park Hospital,}

Slough SL2 4HL

\section{Co-operation over surgical training}

SIR,-In 1972 the Conference of Surgical Colleges met in Cape Town and later in Ottawa and Chicago. These meetings were remarkable. For the first time the American College of Surgeons, represented by its president, joined the Colleges of England, Edinburgh, Glasgow, Ireland, Australasia, Canada, and South Africa and played a full part in the discussions and decisions, the main topic being training for a career in surgery. Not only was there a very great measure of agreement on all important matters but the future appeared bright, with the representatives from all colleges speaking of the value of unity and looking forward to an increasing measure of intercollegiate co-operation. For several years afterwards the pattern had been set and the wish of the colleges to work together governed educational debates and the designing of training programmes and examinations.

But now-what has gone wrong? What has happened to all these good intentions ? Everywhere one looks the spectacle of this surgical college or that taking a decision in isolation, even at times in defiance, of the views of other colleges catches the eye. "Do it our way" is the cry on all sides, or, "Let us abandon unity as an objective."

Another meeting of the Conference of Surgical Colleges is planned for October of this year. We would urge those who represent their colleges to attend it determined to find again that earlier spirit of unity which, if not lost, has at least been temporarily mislaid. The combined wisdom and experience of the colleges represented can lead the surgical world, provided the influence of the conference is exercised as a single unit and that the colleges of which it is composed are seen to be in co-operation rather than competition.

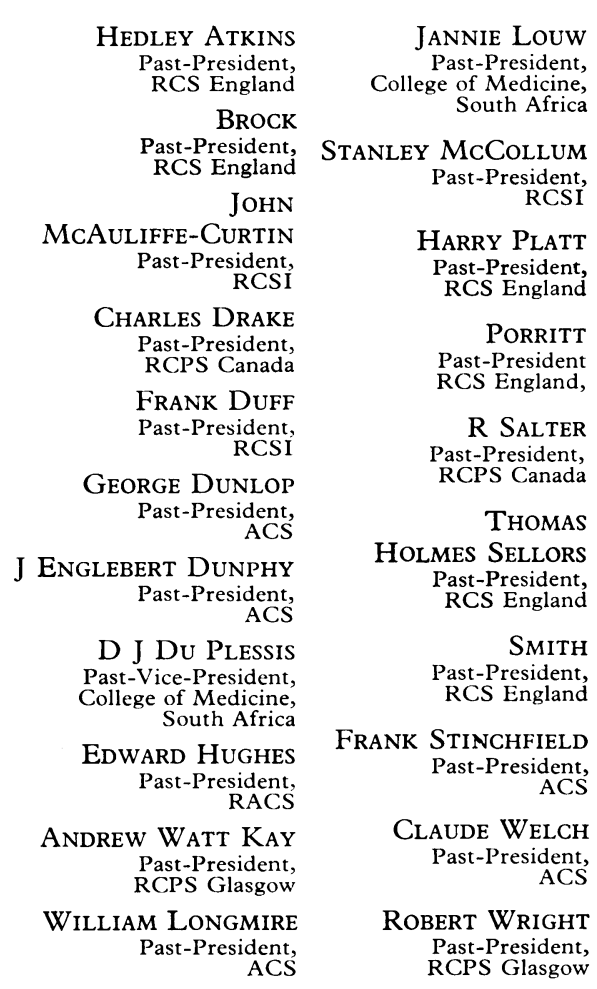

\section{Medical manpower, staffing, and training requirements}

SIR,-In the recent report of a working party on medical manpower (19 May, p 1365), a proposal has been made regarding an attempt to solve the "registrar bulge." At the moment in the popular specialties there are too many registrars competing for the available senior registrar posts, including those hidden by the universities, to guarantee a young trainee a consultant post in a reasonable time. The concept of the policy described is that there will be two types of registrar, those on the register and those outside. The selected trainee would be scrutinised over a period of a year and after that there would be room for him to achieve a consultant post within a reasonable time.

A gross omission is that there appears to be no mention of exercising control over the numbers of occult senior registrar posts in the undergraduate hospitals described as "assistant 